\title{
Temas y Debates tiene ya su propia página web
}

\author{
Adriana Chiroleu \\ Directora de Temas y Debates
}

En los últimos tiempos, las revistas académicas, de análisis, reflexión y propuestas, no sólo se encuentran en nuestro medio en el tradicional formato papel. Además, y facilitando su visibilidad y circulación, el soporte digital es actualmente, cada vez más demandado y puesto en uso.

Por estos motivos, y a partir de la obtención del Premio CLACSO "Juan Carlos Portantiero" de apoyo a revistas de Ciencias Sociales en el año 2009, Temas y Debates estará desde ahora disponible, sin perder su tradicional presentación en papel, en el mundo digital.

A través de la página web de nuestra Facultad: www.fcpolit.unr.edu.ar o en forma directa, ingresando a www.temasydebates.com, es posible encontrar en acceso abierto, datos generales de la revista: periodicidad, bases a las que se encuentra indexada, miembros del Consejo de Redacción, normas editoriales, etc. Además, puede accederse a los números anteriores en forma completa en formato pdf. También encontrarán en la página links a otras publicaciones similares de toda nuestra región con las que Temas y Debates mantiene convenios de canje a través de la Biblioteca de la Facultad de Ciencia Política y Relaciones Internacionales. Esta sección pretende contribuir a generar una mayor visibilidad de la producción académica en los ámbitos de formación e investigación.

Finalmente, la página agilizará la comunicación entre colaboradores y lectores y el Equipo de Edición de la revista pudiendo acceder a un área de Comentarios y, asimismo, a su Suscripción, en donde se ofrecen varias posibilidades de acceso a la revista en formato papel.

Creemos que la posibilidad de contar con una página propia traerá enormes beneficios que, no sólo facilitarán nuestra comunicación con colaboradores y lectores, sino también, con todos aquellos interesados en las problemáticas que rodean la actualidad de las Ciencias Sociales.

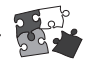

